\title{
Influence of Press Ram Pulsation on Deep Drawability of Dual Phase Steel Sheet
}

\author{
S. Olguner* And A. Tolga Bozdana \\ University of Gaziantep, Department of Mechanical Engineering, Gaziantep, Turkey
}

\begin{abstract}
A study of the influences of press ram pulsation on deep drawability of dual phase steel sheet is presented. General characteristics of deep drawing process, press ram pulsation technique and dual phase steels are briefly discussed. A finite element model is used to evaluate the influence of pulse motion profile of press ram on the thickness reduction of steel sheet and forming load. Commercial finite element software package DEFORM-3D is used for modelling and simulation of cylindrical cup drawing. The effects of superimposed low frequency vibrations of the press ram are investigated. Pulsation amplitudes of $0.5,0.25$, and $0.125 \mathrm{~mm}$ are created on the die with the corresponding pulsation frequencies of 5,10 , and $20 \mathrm{~Hz}$. Finite element simulations are carried out using material model of dual phase (DP600) steel, that is one of the most widely used materials in automobile industry, in order to improve crash safety and fuel economy. Results obtained with press ram pulsation are compared with results for the conventional press ram motion and significant effect of proposed method is demonstrated.
\end{abstract}

DOI: 10.12693/APhysPolA.132.742

PACS/topics: 81.20.Hy, 81.40.Lm, 02.70.Dh

\section{Introduction}

Deep drawing is a sheet metal forming process that is widely used in many fields of manufacturing, especially in automobile industry, to produce car body parts. In this process, sheet metal is drawn into a forming die by the mechanical action of a press. The action of the press ram significantly affects the forming characteristic. However, conventional mechanical presses are not able to offer flexibility of press ram motion and cannot provide reasonable drawing ratios due to early formations of wrinkling and tearing at cup corners. Therefore, use of servo presses has become recently popular in deep drawing processes. Due to precise control of servo motors by means of computers, servo presses are connected by driving with different motions such as link, soft and pulse motions in order to maximize the production efficiency.

Dual phase (DP) steels, being among advanced highstrength steels (AHSS), have been recently used in the sheet metal forming of automotive body parts, for their great benefit in reducing vehicle weight, while improving car safety [1]. DP steels have ferrite-martensite microstructure in which, soft ferritic network provides good ductility; while, hard particles and martensitic phase play the load-bearing role [2]. As a result, DP steels have a combination of special mechanical properties, such as high tensile strength, high work hardening rate, at early stages of plastic deformation, as well as very good ductility. However, in practical application of dual phase steels, one of the major challenges is the formability prediction of onset cracks [1].

At present, many researchers have investigated the effect of pulsation on deep drawing process.

\footnotetext{
*corresponding author; e-mail: olguner@gantep.edu.tr
}

Kriechenbauer et al. [3] described a new technology for deep drawing on servo-screw presses, called "cushion-ram pulsation". In their study, the effects of superimposed low frequency vibrations on deep drawability of DC04 steel sheets, with $10-50 \mathrm{~Hz}$ at cushion and press ram, were investigated. Wrinkles were reduced, and the drawing ratio was increased from 2.1 to 2.4 by the effect of low frequency vibrations. In addition, in order to ensure a greater efficiency in deep drawing operations, it was stated that the higher frequency vibrations, acting on punch and blank holder, should be preferred.

Mostafapur et al. [4] have investigated the effect of pulsating blankholder system on improving the formability of aluminium 1050 alloy. Deep drawing of cylindrical cup was also simulated by ABAQUS software. The result indicated that by using the pulsating blankholder system, coupled with proper frequency and gap, the cup depth can be increased and thickness distribution can be improved.

Ali et al. [5] have experimentally studied the effect of the frequency pulses under $10 \mathrm{~Hz}$ on formability of aluminum sheets. Hydraulic actuators were used to pulsate the blankholder. The results showed that with $30 \mathrm{kN}$ blankholder force and $20 \mathrm{kN}$ amplitude, and $0.3,0.25$ and $0.15 \mathrm{~Hz}$ frequencies, the respective drawing depths of 36,44 , and $60 \mathrm{~mm}$ were achieved without fracture.

Yagami et al. [6] have investigated the effect of alternating blank holder motion on deep drawability wrinkle elimination. Experimental deep drawing tests have been carried out on $\mathrm{Cu}$ alloy sheets. The results of the experiment indicated that wrinkle elimination can be successful if wrinkles are within the allowable height range.

Fang et al. [7] have carried out a study on the electromagnetic pulse-assisted progressive deep drawing of aluminium alloy sheets. The results show that the placement of the radial thrust coil has significant effect on the sheet metal state and distribution of stress-strain. In addition, 
the interaction of the axial drawing force and the radial thrusting force has great effect on the depth of the deep drawing cylindrical parts.

As discussed above, there are many studies attempting to use pulsation methods in deep drawing process. However, in all these studies, aluminium alloys, copper alloys and cold rolled steel for deep drawing quality have been selected as sheet materials to utilize in deep drawing tests. There are no studies examining the effects of pulsation on deep drawing of DP steels. In the present work, influences of pulsation on forming load and the thickness reduction at the punch corner section, which is the common factor for failure prediction of DP600 sheets in deep drawing process, were investigated through finite element approach.

\section{Finite element analysis}

Finite element analyses have recently been used for many purposes, such as structural strength analyses, fatigue life calculations, thermal modelling and design improvements [8-12]. In the present study, finite element analyses are utilized for sheet metal forming simulations. A three dimensional finite element method is adopted. Four different finite element analyses of pulsation-assisted deep drawing process are carried out by DEFORM-3D commercial finite element analysis package. As shown in Fig. 1, a quarter section of the sheet blank is analyzed using symmetric plane boundary conditions, instead of modelling the whole geometry, in order to shorten simulation time.

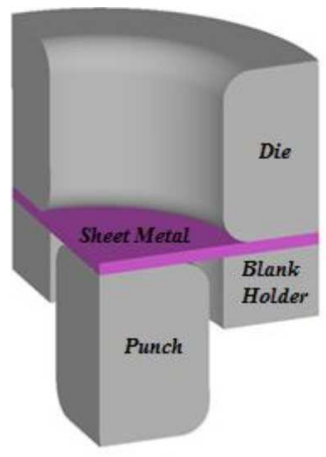

(a)

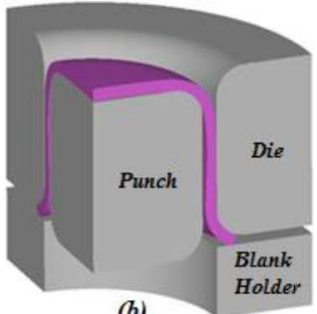

(b)
Fig. 1. Finite element model of cylindrical cup, (a) before deformation, (b) after deformation.

In order to prevent wrinkling of the sheet material, a constant $20000 \mathrm{~N}$ blank holder force is applied to blank holder. The coefficient of friction between forming tools and blank is assumed to be 0.08, by adopting shear friction model. The forming speed is set to $10 \mathrm{~mm} / \mathrm{s}$ in forward and backward directions. Tetrahedral fournode three dimensional elements are used in the mesh of the solid structure of the sheet blank. The total number of elements is 85583 with 19569 nodes. Frequencies and amplitudes of pulsations are tabulated in Table I and press ram motion profiles are illustrated in Fig. 2.

TABLE I

Frequencies and amplitudes of case studies.

\begin{tabular}{c|c|c|c|c}
\hline \hline & Case 1 & Case 2 & Case 3 & Case 4 \\
\hline Frequency [Hz] & - & 5 & 10 & 20 \\
Amplitude [mm] & - & 0.5 & 0.25 & 0.125
\end{tabular}
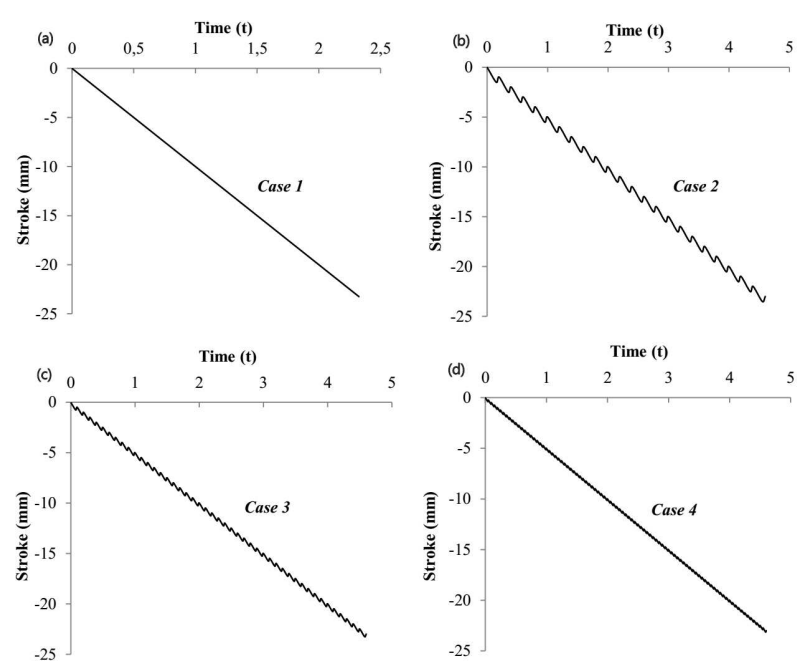

Fig. 2. Press ram motion profiles.

\subsection{Material properties}

Punch, die and blank holder are assumed to be rigid and DP600 sheet blank has elasto-plastic material model. The flow curve of the sheet metal may be defined as [13]:

$$
\sigma=K \varepsilon^{n} \dot{\varepsilon}^{m}+y,
$$

where $\sigma$ is the true stress, $K$ is the strength coefficient, $\varepsilon$ is the total plastic strain, $n$ is the hardening coefficient, $\dot{\varepsilon}$ is the strain rate, $m$ is the strain rate coefficient and $y$ is the yield strength of the material.

Hill's quadratic yield criterion is used with kinematic hardening model. The mechanical properties of DP600 steel are given in Table II.

TABLE II

The mechanical properties of DP600 steel [1, 14].

\begin{tabular}{|c|c|c|c|c|c|c|c|c|c|c|}
\hline \multirow{2}{*}{$\begin{array}{c}\text { Yield } \\
\text { strength } \\
\text { [MPa] }\end{array}$} & \multirow{2}{*}{$\begin{array}{c}\text { Ultimate } \\
\text { strength } \\
{[\mathrm{MPa}]}\end{array}$} & \multirow{2}{*}{$\begin{array}{c}\text { Young } \\
\text { modulus } \\
E[\mathrm{GPa}]\end{array}$} & \multirow{2}{*}{$\begin{array}{c}\text { Total } \\
\text { elongation } \\
\delta[\%]\end{array}$} & \multirow{2}{*}{$\begin{array}{c}\text { Poisson's } \\
\text { ratio } \\
v\end{array}$} & \multirow{2}{*}{$\begin{array}{c}K \\
\text { value }\end{array}$} & \multirow{2}{*}{$\begin{array}{c}n \\
\text { value }\end{array}$} & \multirow{2}{*}{$\begin{array}{c}m \\
\text { value }\end{array}$} & \multicolumn{3}{|c|}{$\begin{array}{c}\text { Lankford } \\
\text { coefficients }\end{array}$} \\
\hline & & & & & & & & r00 & $\mathrm{r} 45$ & r90 \\
\hline 412 & 665 & 207 & 27 & 0.3 & 1125 & 0.205 & 0.0072 & 1.16 & 0.67 & 1.02 \\
\hline
\end{tabular}




\subsection{Die and blank sizes for analyses}

Thickness of the blank for deep drawing analyses is $1.7 \mathrm{~mm}$. The diameters of the punch and die hole are $31 \mathrm{~mm}$ and $35 \mathrm{~mm}$, respectively and radius of each corner is $3 \mathrm{~mm}$. Initial diameters of the sheet metal are $62 \mathrm{~mm}$ and the diameters of the drawn cups are $31 \mathrm{~mm}$. Thus, drawing ratios in all analyses are equal to 2. Drawing depth of $23.25 \mathrm{~mm}$ is completed in all case studies.

\section{Results and discussion}

Finite element analyses have been performed for four different case studies. The variations of drawing force during forming and the minimum drawing force, required to accomplish operations, have been determined. Thickness reductions of the sheet blanks at punch corner region have been also investigated.

\subsection{Drawing force}

Drawing force variations for the reference condition, without pulsation and for three different pulsation cases are shown in Fig. 3. It is seen from the figure that the application of low frequency vibration decreases the required drawing force significantly. Also, the increase of pulsation frequency with the reduction of amplitude provides further decrease in drawing force. The required drawing force is $192 \mathrm{kN}$ for the reference condition (Case 1) without pulsation. It decreases to $186 \mathrm{kN}$ for Case 2, $182 \mathrm{kN}$ for Case 3 and $179 \mathrm{kN}$ for Case 4. It is observed that the application of pulsation with $20 \mathrm{~Hz}$ frequency and $0.125 \mathrm{~mm}$ amplitude provides a reduction of about $7 \%$ in drawing force.
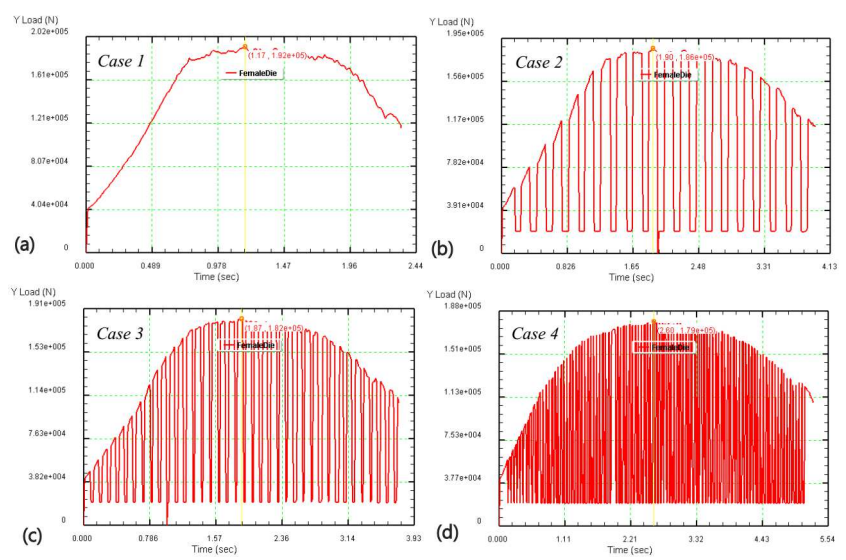

Fig. 3. Drawing force variation during forming, for different amplitudes and frequencies.

\subsection{Thickness reduction}

Thickness reduction of the blank is the common factor for failure prediction in sheet metal forming processes. It is the most influential factor, determining the forming limits of the material. Figure 4 shows the strain distribution of the drawn cup. It is seen from the figure that the punch corner region is the most critical section in the regard of thickness reduction. Therefore, reduction of thickness at punch corner section is examined. It has been detected that the application of low frequency pulsation causes lower thickness reduction of sheet metal. Material thickness of $1.7 \mathrm{~mm}$ is decreased to $1.228 \mathrm{~mm}$ for reference condition (Case 1) without pulsation, which corresponds to $27.8 \%$ of reduction. In other cases, it is reduced to $1.257 \mathrm{~mm}$ (26.1\%), $1.280 \mathrm{~mm}(24.7 \%)$, and $1.293 \mathrm{~mm}(23.9 \%)$ for Cases 2, 3, and 4, respectively. Thus, the increase of vibration frequency with the decrease of amplitude provides further decrease in thickness reduction of sheet metal.

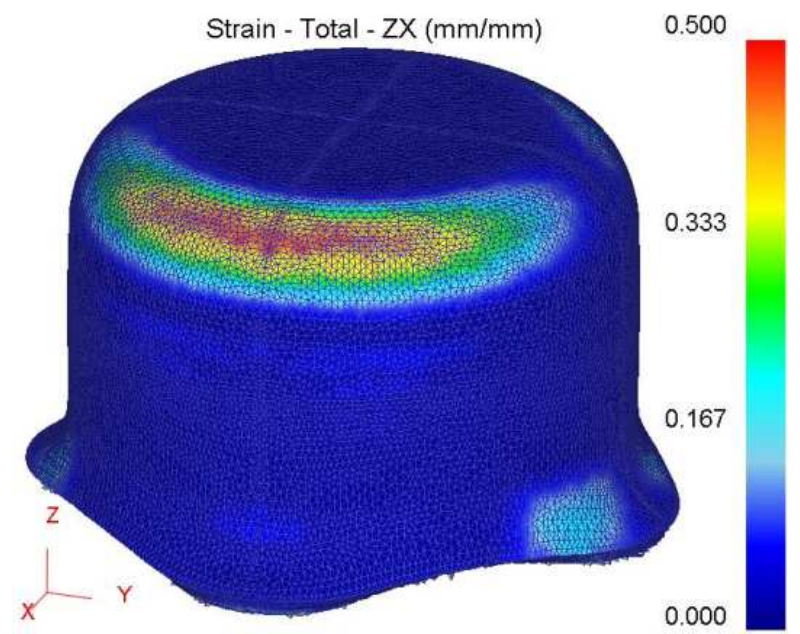

Fig. 4. Strain distribution of the drawn cup.

\section{Conclusions}

The required drawing force and thickness reduction for pulsation-assisted deep drawing of a cylindrical cup were studied by a numerical approach. A finite element model is generated and analyses of four different cases were carried out by changing frequency and amplitude of pulsations applied to the die. Elasto-plastic finite element analyses have been performed in DEFORM-3D. It has been observed that the pulsation with frequency of $20 \mathrm{~Hz}$ and amplitude of $0.125 \mathrm{~mm}$ results in about $7 \%$ decrease in drawing force. Also, it is clear from the analyses that application of such vibrations leads to lower reduction in thickness of the sheet metal. Thickness reduction in case of no pulsation was reduced from $27.8 \%$ to $23.9 \%$ by means of applying pulsations of $20 \mathrm{~Hz}$. Further investigations on the developed models are in progress in order to improve the effectiveness of such analyses.

\section{Acknowledgments}

The authors would like to thank The Scientific and Technological Research Council of Turkey (TUBITAK) for fully financing this work under the project number of $315 \mathrm{M} 300$. 


\section{References}

[1] W.R. Wang, C.W. He, Z.H. Zhao, X.C. Wei, Mater. Design 32, 3320 (2011).

[2] T. Baudin, C. Quesnea, J. Jura, R. Penelle, Mater. Charact. 47, 365 (2001).

[3] S. Kriechenbauer, R. Mauermann, P. Muller, Procedia Engin. 81, 905 (2014).

[4] A. Mostafapur, S. Ahangar, R. Dadkhah, Int. J. Adv. Manuf. Technol. 69, 1113 (2013).

[5] S. Ali, S. Hinduja, J. Atkinson, P. Bolt, R. Werkhoven, Int. J. Mach. Tools Manufact. 48, 558 (2008).

[6] T. Yagami, K. Manabe, Y. Yamauchi, J. Mater. Proc. Technol. 187, 187 (2007).
[7] F. Jinxiu, M. Jianhua, L. Jianjun, C. Xiaohui, F. Suo, Procedia Engin. 81, 801 (2014).

[8] M. Ozsoy, K. Pehlivan, M. Firat, N. Ozsoy, V. Ucar, Acta Phys. Pol. A 128, 327 (2015).

[9] O. Karacali, Acta Phys. Pol. A 128, B-40 (2015).

[10] O. Karacali, Acta Phys. Pol. A 130, 249 (2016).

[11] B. Nagy, Acta Phys. Pol. A 128, B-164 (2015).

[12] M. Urbanek, D. Blaszkiewicz, Acta Phys. Pol. A 128, B-241 (2015).

[13] DEFORM-3D, Ver. 6.1 User's Manual, Columbus, Ohio 2008.

[14] K. Bandyopadhyay, S.K. Panda, P. Saha, G. Padmanabham, J. Mater. Proc. Technol. 217, 48 (2015). 